\title{
Patient-Reported Outcome Measures for Chronic Obstructive Pulmonary Disease
}

\author{
The Exclusion of People with Low Literacy Skills and Learning Disabilities
}

\author{
Deepa Jahagirdar · Thilo Kroll · Karen Ritchie • \\ Sally Wyke
}

Published online: 16 February 2013

(c) The Author(s) 2013. This article is published with open access at Springerlink.com

\begin{abstract}
Background Patient-reported outcome measures (PROMs) are intended to reflect outcomes relevant to patients. They are increasingly used for healthcare quality improvement. To produce valid measures, patients should be involved in the development process but it is unclear whether this usually includes people with low literacy skills or learning disabilities. This potential exclusion raises concerns about whether these groups will be able to use these measures and participate in quality improvement practices.

Methods Taking PROMs for chronic obstructive pulmonary disease (COPD) as an exemplar condition, our review determined the inclusion of people with low literacy skills and learning disabilities in research developing, validating, and using 12 PROMs for COPD patients. The studies included in our review were based on those identified in two existing systematic reviews and our update of this search.

Results People with low literacy skills and/or learning disabilities were excluded from the development of PROMs in two ways: explicitly through the participant eligibility criteria and, more commonly, implicitly through recruitment or administration methods that would require high-level reading and cognitive abilities. None of the
\end{abstract}

D. Jahagirdar $\cdot$ S. Wyke $(\bowtie)$

Institute of Health and Wellbeing, College of Social Science,

University of Glasgow, 25 Bute Gardens,

Glasgow G12 8RS, UK

e-mail: sally.wyke@glasgow.ac.uk

T. Kroll

Social Dimensions of Health Institute, University of Dundee,

Dundee, UK

K. Ritchie

Healthcare Improvement Scotland, Glasgow, UK studies mentioned efforts to include people with low literacy skills or learning disabilities.

Conclusion Our findings suggest that people with low literacy skills or learning disabilities are left out of the development of PROMs. Given that implicit exclusion was most common, researchers and those who administer PROMs may not even be aware of this problem. Without effort to improve inclusion, unequal quality improvement practices may become embedded in the health system.

\section{Key Points for Decision Makers}

- Patient-reported outcome measures (PROMs) are health questionnaires asking patients to report on their symptoms and quality of life

- Normally patients are involved in the rigorous process to develop PROMs to ensure the questionnaires make sense and are relevant to them. However, this study demonstrates that people with low literacy skills and learning disabilities are generally left out of the development of PROMs so they may not be able to use these measures

- Increased involvement of these groups in research and specific efforts to ensure PROMs are accessible for them could prevent unequal access to further uses of PROMs, for example, in healthcare quality improvement

\section{Background}

Patient-reported outcome measures (PROMs) are quickly becoming an important part of healthcare quality 
improvement processes internationally [1]. Health professionals and authorities can use these questionnaires to understand the burden of disease from the patients' perspective and gather information to improve the quality of care they receive. Although PROMs are mainly used for acute conditions, expanding their use into long-term conditions is imminent [2].

Multiple stages involving patients and subject experts are required to develop PROMs so that they will produce meaningful data. Typically, developers first consult with the concerned groups about what to include in the PROM. Several forms of validation and reliability testing follow before the PROM is finalized. The development of a PROM does not stop at its conception; the process of development is ongoing, encompassing further validation and reliability testing of PROMs through use with different patient groups. The initial and ongoing development and validation are meant to ensure the items and tool are meaningful to clinicians and patients and that it is easy to administer [3]. Since patients are consulted, PROM development appears patient centered. But not all groups of patients may have an opportunity to offer their views on PROMs.

People with low literacy skills or learning disabilities may be excluded from PROM development and ultimately from the uses of PROMs, countering national and international policies. The causes of learning disability and low literacy vary greatly, and people with low literacy and those with learning disabilities are not usually grouped together. Nevertheless, the functional difficulties (e.g., reading ability and comprehension) they face can be similar and both groups may find help in processing written material and managing health interventions useful [4]. Together, these groups form a large proportion of people in the UK, where one in five adults have low literacy skills [5] and there are approximately 1.5 million people with learning disabilities [6]. Literacy difficulties are associated with general exclusion from trials and research [7]. If people with low literacy skills or learning disabilities are left out of the development of PROMs specifically, they may struggle to complete them since patient involvement is crucial to ensure appropriate wording, format, and other needs are met. When PROMs are then used in further healthcare initiatives, they may face exclusion again. This exclusion would counter the UK Government's policy for the NHS to achieve full inclusion [8]. It also violates the principles outlined in the United Nations Convention on the Rights of Persons with Disabilities [9].

To prevent people with low literacy skills and/or learning disabilities from possible exclusion from PROMs initiatives, knowledge of the extent and nature of exclusion in the development of PROMs is required. There is little previous research on this issue in the PROMs literature.
Others have, however, acknowledged the potential for the exclusion of people with low literacy skills and learning disabilities from PROMs initiatives. Devlin and Appleby [10] write that gathering PROMs data from people with "cognitive deficits" (p. 12) is difficult. Mencap, a leading charity in the UK for people with learning disabilities, say their clients are at risk of being left out of efforts to gather health information from patients [11]. But neither describes the current extent of exclusion from the development of PROMs in the first place.

Chronic obstructive pulmonary disease (COPD) is a good exemplar case to investigate potential exclusion. This long-term condition causes significant burden to over 3 million people in the UK [12]. It is also more prevalent in lower socio-economic groups where lower levels of literacy are also more common. This study examines the most commonly used PROMs for COPD to investigate whether there is systematic exclusion of people with learning disabilities and/or low literacy from PROM use and, if so, aims to suggest how PROMs can be developed more inclusively.

\section{Method}

Our methods had two phases.

In Phase I, we identified the existing PROMs that are considered suitable for use with people with COPD using systematic reviews by Fitzpatrick et al. [13] and Davies et al. [14]. The most promising PROMs they identified included the respiratory condition-specific Clinical Respiratory Questionnaire (CRQ) and St George's Respiratory Questionnaire (SGRQ), and the generic EQ-5D and SF-36. We went through Fitzpatrick et al. [13] and Davies et al.'s [14] reference lists to select only the publications involving the above-listed PROMs. The inclusion and exclusion criteria are summarized in Table 1. Given the quality of their review, these were the basis for our study for articles published prior to or in 2008 .

In Phase II, we updated the search to identify papers describing PROMs developed from 2009 to 2012. To identify these papers, we used a pragmatic approach based on the search strategy provided to us by one of the authors of Davies et al. [14], searching in MEDLINE. We were not in a position to recommend which of the newly identified PROMs were suitable for population use, as was done in Fitzpatrick et al. [13] and Davies et al. [14], so we included all PROMs that were used with COPD patients, were in English, and were not too narrowly focused (for example, focusing only on one or two specific symptoms such as breathlessness). We also included two PROMs that were identified, but had only just been developed, at the end of Davies et al.'s [14] systematic review in 2009: the COPD 
Table 1 Inclusion and exclusion criteria for the papers identified in Phases I and II

COPD chronic obstructive pulmonary disease, PROM patient-reported outcome measure

a These criteria were applied to the papers previously identified in Fitzpatrick et al. [13] and Davies et al. [14] until 2008

b These were not differentiated; both are included as 'CRQ'

c These were not differentiated; both are included as 'SGRQ'

d These criteria were applied to papers describing and using PROMs developed from 2009 to 2012

\begin{tabular}{|c|c|}
\hline Inclusion criteria & Exclusion criteria \\
\hline \multicolumn{2}{|l|}{ Phase $I^{\mathrm{a}}$} \\
\hline $\begin{array}{l}\text { Study with primary research involving patients } \\
\text { or members of the public }\end{array}$ & $\begin{array}{l}\text { Included PROM only to validate another } \\
\text { PROM that was not relevant to our study }\end{array}$ \\
\hline Inclusion of one or more of the following PROMs: & Systematic reviews \\
\hline \multicolumn{2}{|l|}{ Condition specific: } \\
\hline \multicolumn{2}{|l|}{$\begin{array}{l}\text { - Chronic Respiratory Disease } \\
\text { Questionnaire (CRQ) }\end{array}$} \\
\hline \multicolumn{2}{|l|}{$\begin{array}{l}\text { - Short-Form Chronic Respiratory Disease } \\
\text { Questionnaire (SF-CRQ) }\end{array}$} \\
\hline \multicolumn{2}{|l|}{ - St George's Respiratory Questionnaire (SGRQ) ${ }^{\mathrm{c}}$} \\
\hline \multicolumn{2}{|l|}{$\begin{array}{l}\text { - COPD-specific St George's Respiratory } \\
\text { Questionnaire (SGRQ-C) }{ }^{\mathrm{c}}\end{array}$} \\
\hline \multicolumn{2}{|l|}{ Generic: } \\
\hline \multicolumn{2}{|l|}{ - SF-36 } \\
\hline \multicolumn{2}{|l|}{$\bullet$ EQ-5D } \\
\hline \multicolumn{2}{|l|}{ Phase $I I^{\mathrm{d}}$} \\
\hline $\begin{array}{l}\text { Study with primary research involving patients } \\
\text { or members of the public }\end{array}$ & $\begin{array}{l}\text { Included PROM only to validate another } \\
\text { PROM that was not relevant to our study }\end{array}$ \\
\hline Inclusion of one or more of the following PROMs: & Systematic reviews \\
\hline - McGill COPD Quality of Life Questionnaire & \\
\hline $\begin{array}{l}\text { - Functional Assessment of Chronic Illness } \\
\text { Therapy (FACIT)-Dyspnea Scale }\end{array}$ & \\
\hline \multicolumn{2}{|l|}{ - Disability Related to COPD Tool (DIRECT) } \\
\hline \multicolumn{2}{|l|}{$\begin{array}{l}\text { - Capacity of Daily Living during the } \\
\text { Morning Questionnaire }\end{array}$} \\
\hline \multicolumn{2}{|l|}{$\begin{array}{l}\text { - Visual Simplified Respiratory } \\
\text { Questionnaire (VSRQ) }\end{array}$} \\
\hline \multicolumn{2}{|l|}{ - Living with COPD Questionnaire } \\
\hline \multicolumn{2}{|l|}{ - COPD Assessment Test (CAT) } \\
\hline \multicolumn{2}{|l|}{$\begin{array}{l}\text { - EXAcerbations of Chronic Obstructive } \\
\text { Pulmonary Disease Tool (EXACT) }\end{array}$} \\
\hline Study was published between 2009 and 2012 & \\
\hline
\end{tabular}

Assessment Test (CAT) and the EXAcerbations of Chronic Obstructive Pulmonary Disease Tool (EXACT). The inclusion and exclusion criteria for this phase are also summarized in Table 1.

The abstracts from Phase I and Phase II were independently reviewed by two researchers for inclusion and exclusion. If there was a discrepancy, the abstract went to a third reviewer to decide. We retrieved the full text of articles that met the inclusion criteria and extracted the relevant data from each paper including:

1. The aim of the study

2. The PROM(s) used

3. The participant recruitment and data collection processes (if stated)

4. The inclusion and exclusion criteria for research participants (if stated)
5. Any mention of people with low literacy skills or learning disabilities

We distinguished between 'explicit' and 'implicit' modes of exclusion. Studies were classed as having 'explicit exclusion' if they excluded people with low literacy skills or learning disabilities 'explicitly' or immediately as a result of the study's eligibility criteria. While we did not consider a specific category of disability severity, the terms considered to imply the potential exclusion of groups with low literacy skills or learning disabilities included those who were 'unable to read,' or 'unable to complete or comprehend the questionnaire,' or those with 'cognitive deficits,' 'cognitive impairments,' or 'cognitive limitations.' Studies that used literacy-dependent methods for recruitment or data collection (e.g., unassisted self-completion of the PROM) were classed as leading to 'implicit exclusion.' 


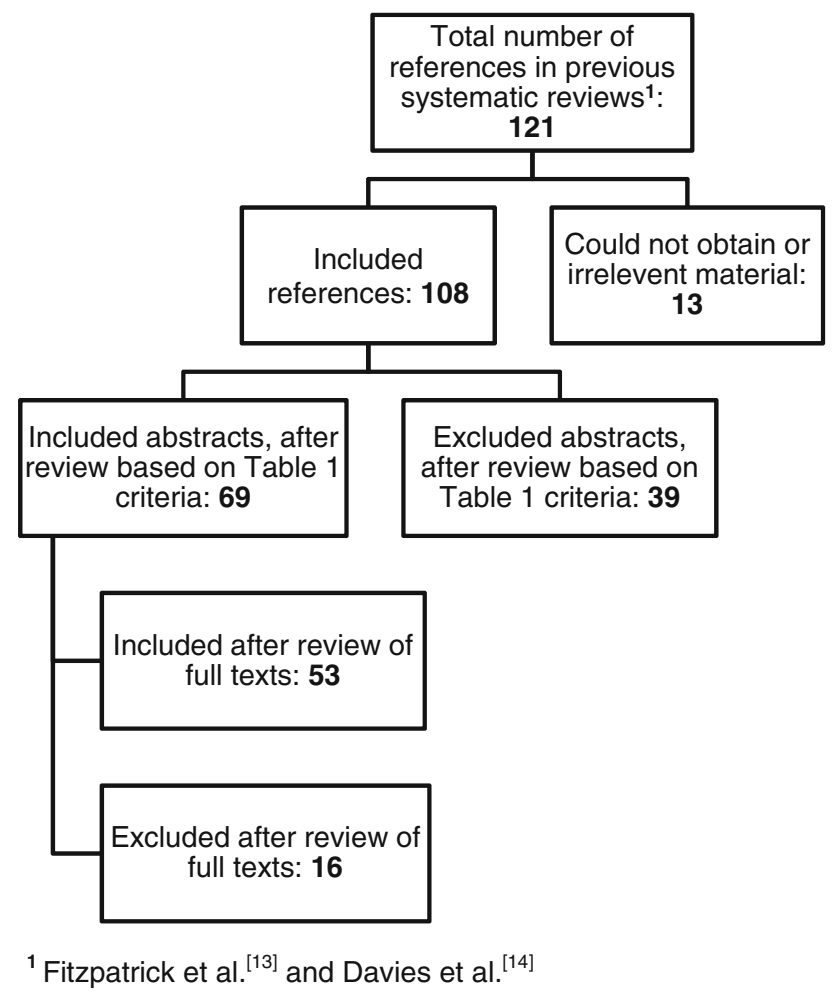

Fig. 1 Phase I review flow chart

A second researcher in the team checked the data extraction for $20 \%$ of the articles. Finally anything else in the study set-up that could impact the inclusion of these groups was recorded.

\section{Results}

We reviewed 108 abstracts and included 53 papers in Phase I. We identified six new PROMs in Phase II and reviewed 67 abstracts, eventually including 17 papers. The processes for Phase I and Phase II are summarized in Figs. 1 and 2, respectively. In addition to the CRQ, SGRQ, EQ-5D, SF-36, CAT, and EXACT tools, the new PROMs identified and included were:

1. The McGill COPD Quality of Life Questionnaire

2. The Functional Assessment of Chronic Illness Therapy (FACIT)-Dyspnea Scale

3. The Disability Related to COPD Tool (DIRECT)

4. The Capacity of Daily Living during the Morning Questionnaire

5. The Visual Simplified Respiratory Questionnaire (VSRQ)

6. The Living with COPD Questionnaire

We extracted data from 70 papers in total. None of the studies mentioned specific efforts to include people with low literacy skills or learning disabilities. Three studies

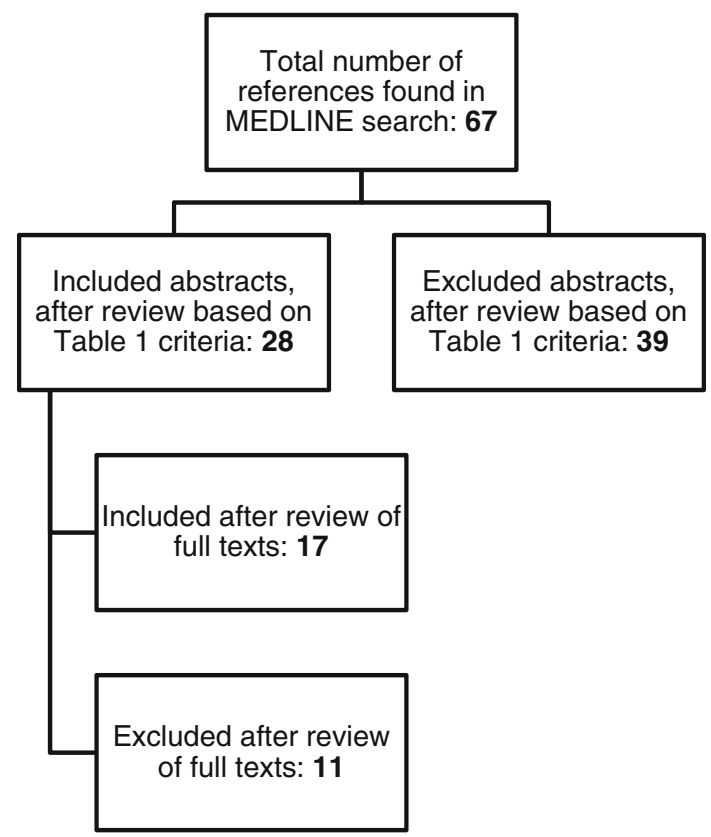

Fig. 2 Phase II review flow chart

excluded these groups explicitly, or based on eligibility criteria alone. For example Aaron et al. [15] excluded those with cognitive impairments. Thirty-two studies had implicit exclusion only, relating to non-inclusive recruitment and questionnaire administration processes. For instance Schofield and Mishra [16] recruited study participants through postal packages. People with low literacy skills or learning disabilities may not be able to read or comprehend such packages excluding them from the study at the outset; other examples included recruitment through newspaper advertisements [17] and the requirement for self-administration [18], which was the most common reason for classifying studies as having implicit exclusion. Sixteen studies had both explicit and implicit exclusion. Finally, 19 studies were unclear about recruitment or administration processes so we could not verify whether they excluded people with low literacy skills or learning disabilities (Table 2).

We also recorded other notable issues in the studies concerning people with low literacy skills and learning disabilities. Some of the studies' protocols may have given consideration for these groups. For example, Aiken et al. [19] used telephone interviews to administer the PROM, although they did not accept proxy responses. Williams et al. [20] provided an opportunity for participants to clarify the self-administered questionnaire at the end. Some studies also described the sample composition, which could give an indication of the prevalence of low literacy. In Sprenkle et al. [21], the majority of participants had minimum high school education, while $26 \%$ of Wyrwich et al.'s [22] sample had a grade school education only. 
Table 2 Data extraction results

\begin{tabular}{|c|c|c|c|c|c|}
\hline Study & PROMs involved & $\begin{array}{l}\text { Explicit } \\
\text { exclusion }\end{array}$ & $\begin{array}{l}\text { Implicit } \\
\text { exclusion }\end{array}$ & $\begin{array}{l}\text { Unclear } \\
\text { or no } \\
\text { evidence } \\
\text { of } \\
\text { exclusion }\end{array}$ & Notes \\
\hline Aaron et al. [15] & CRQ & $X$ & & & - Excluded those with cognitive impairments \\
\hline Aguilaniu et al. [37] & DIRECT & & $\mathrm{X}$ & & - Self-administration \\
\hline Aiken et al. [19] & SF-36 & & $\mathrm{X}$ & & - Proxy responses not accepted \\
\hline Ashmore. et al. [38] & SF-36 & & $\mathrm{X}$ & & - Self-administration \\
\hline Berry et al. [39] & CRQ & & $\mathrm{X}$ & & $\begin{array}{l}\text { - Recruited through media advertising } \\
\text { - Self-administration }\end{array}$ \\
\hline Bauldoff et al. [40] & SGRQ & $X$ & & & $\begin{array}{l}\text { - Excluded those with inability to read or } \\
\text { cognitive impairments }\end{array}$ \\
\hline Benzo et al. [41] & SF-36 & & $X$ & & - Self-administration \\
\hline Brightling et al. [42] & CRQ & & & $X$ & \\
\hline Brown et al. [43] & SF-36, SGRQ & & $\mathrm{X}$ & & - Self-administration \\
\hline Carr et al. [44] & CRQ & $X$ & $\mathrm{X}$ & & $\begin{array}{l}\text { - } 19 / 234 \text { were excluded due to cognitive } \\
\text { impairments } \\
\text { - Self-administration } \\
\text { - Excluded those who could not } \\
\text { communicate clearly }\end{array}$ \\
\hline $\begin{array}{l}\text { Carrieri-Kohlman } \\
\text { et al. [45] }\end{array}$ & CRQ, SF-36 & & & $X$ & \\
\hline Coultas et al. [46] & SGRQ, SF-36 & & $X$ & & - Recruited through postal mail-outs \\
\hline Crockett et al. [47] & SF-36 & $X$ & $\mathrm{X}$ & & $\begin{array}{l}\text { - Excluded those who were not mentally able } \\
\text { to complete questionnaires } \\
\text { - Postal questionnaires }\end{array}$ \\
\hline de Torres et al. [48] & SF-36, SGRQ, CRQ & $X$ & $X$ & & $\begin{array}{l}\text { - Excluded those who could not complete } \\
\text { questionnaires } \\
\text { - Self-administration }\end{array}$ \\
\hline Desikan et al. [49] & SF-36, SGRQ and CRQ & & $\mathrm{X}$ & & - Recruited through postal mail-outs \\
\hline Dodd et al. [50] & CAT & & $\mathrm{X}$ & & - Self-administration \\
\hline Eaton et al. [51] & CRQ & $\mathrm{X}$ & $\mathrm{X}$ & & $\begin{array}{l}\text { - Excluded those who could not complete } \\
\text { questionnaires } \\
\text { - Self-administration }\end{array}$ \\
\hline Fan et al. [52] & SGRQ & & & $\mathrm{X}$ & \\
\hline Gross et al. [53] & SGRQ & & & $X$ & \\
\hline Gupta et al. [54] & CRQ & & $\mathrm{X}$ & & - Self-administration \\
\hline Guyatt et al. [55] & CRQ & & & $X$ & \\
\hline Guyatt et al. [56] & CRQ & & & $\mathrm{X}$ & \\
\hline Harper et al. [57] & CRQ, SGRQ, SF-36, EQ-5D & & $\mathrm{X}$ & & - Self-administration \\
\hline Hazell et al. [58] & EQ-5D & & $\mathrm{X}$ & & $\begin{array}{l}\text { - Self-administration } \\
\text { - Recruitment and questionnaire completion } \\
\text { through the post }\end{array}$ \\
\hline Hinchcliff et al. [59] & FACIT-Dyspnea Scale & & $\mathrm{X}$ & & - Self-administration \\
\hline Johnson et al. [60] & SGRQ & & & $X$ & \\
\hline Jones et al. [61] & SGRQ & & & $X$ & \\
\hline Jones and Bosh [62] & SGRQ, SF-36 & & $X$ & & - Self-administration \\
\hline Jones et al. [63] & CAT & & & $X$ & \\
\hline Jones et al. [64] & CAT & & $X$ & & - Self-administration \\
\hline Jones et al. [65] & CAT & & & $X$ & \\
\hline
\end{tabular}


Table 2 continued

\begin{tabular}{|c|c|c|c|c|c|}
\hline Study & PROMs involved & $\begin{array}{l}\text { Explicit } \\
\text { exclusion }\end{array}$ & $\begin{array}{l}\text { Implicit } \\
\text { exclusion }\end{array}$ & $\begin{array}{l}\text { Unclear } \\
\text { or no } \\
\text { evidence } \\
\text { of } \\
\text { exclusion }\end{array}$ & Notes \\
\hline Leidy et al. [66] & EXACT & $X$ & $\mathrm{X}$ & & $\begin{array}{l}\text { - Excluded those with an inability to read or } \\
\text { cognitive limitations } \\
\text { - Self-administration }\end{array}$ \\
\hline $\begin{array}{l}\text { Mahler and } \\
\text { Mackowiak [67] }\end{array}$ & SF-36 & & $\mathrm{X}$ & & - Self-administration \\
\hline $\begin{array}{l}\text { Maleki-Yazdi et al. } \\
\text { [17] }\end{array}$ & SGRQ & & $\mathrm{X}$ & & $\begin{array}{l}\text { - Self-administration } \\
\text { - Recruitment through media advertising }\end{array}$ \\
\hline Martin [68] & CRQ & & $\mathrm{X}$ & & - Self-administration \\
\hline McGlone et al. [69] & SGRQ & $\mathrm{X}$ & & & $\begin{array}{l}\text { - } 4 \text { were excluded because they were unable } \\
\text { to read }\end{array}$ \\
\hline McKenna et al. [70] & Living with COPD Questionnaire & $X$ & $\mathrm{X}$ & & $\begin{array}{l}\text { - Excluded people who could not read or } \\
\text { respond to questionnaires } \\
\text { - Self-administration }\end{array}$ \\
\hline Miller et al. [71] & CRQ, SF-36 & & $X$ & & - Self-administration \\
\hline Nagata et al. [72] & CAT & $X$ & $X$ & & $\begin{array}{l}\text { - Excluded those who could not read or } \\
\text { understand the questionnaire } \\
\text { - Self-administration }\end{array}$ \\
\hline $\begin{array}{l}\text { Okubadejo et al. } \\
\text { [73] }\end{array}$ & SGRQ & $X$ & $\mathrm{X}$ & & $\begin{array}{l}\text { - Excluded those with an inability to read } \\
\text { - Self-administration }\end{array}$ \\
\hline Pakhale et al. [74] & $\begin{array}{l}\text { McGill COPD Quality of Life } \\
\text { Questionnaire }\end{array}$ & & & $X$ & \\
\hline Partridge et al. [25] & $\begin{array}{l}\text { Capacity of Daily Living during the } \\
\text { Morning Questionnaire }\end{array}$ & & $\mathrm{X}$ & & - Self-administration \\
\hline Perez et al. [75] & VSRQ & & & $X$ & \\
\hline $\begin{array}{l}\text { Petrillo and Cairns } \\
\text { [76] }\end{array}$ & EXACT & $X$ & $X$ & & $\begin{array}{l}\text { - Self-administration } \\
\text { - } 2 \text { removed for lack of comprehension }\end{array}$ \\
\hline Puhan et al. [77] & CRQ, SGRQ, SF-36 & $X$ & $X$ & & $\begin{array}{l}\text { - } 2 \text { were excluded because they were unable } \\
\text { to read } \\
\text { - Self-administration }\end{array}$ \\
\hline Punekar et al. [78] & EQ-5D & & $X$ & & - Self-administration \\
\hline Ries et al. [79] & SGRQ, SF-36 & & $X$ & & - Self-administration \\
\hline Ringbaek et al. [23] & CAT & $X$ & $\mathrm{X}$ & & $\begin{array}{l}\text { - Excluded those who could not read } \\
\text { - Self-administration }\end{array}$ \\
\hline Roth et al. [80] & SGRQ, SF-36 & & & $X$ & \\
\hline $\begin{array}{l}\text { Schofield and } \\
\text { Mishra [16] }\end{array}$ & SF-36 & & $X$ & & $\begin{array}{l}\text { - Self-administration } \\
\text { - Recruitment through postal mail-outs }\end{array}$ \\
\hline $\begin{array}{l}\text { Schunemann et al. } \\
\text { [81] }\end{array}$ & CRQ, SGRQ & $X$ & $X$ & & $\begin{array}{l}\text { - Excluded those with cognitive limitations } \\
\text { - Self-administration }\end{array}$ \\
\hline $\begin{array}{l}\text { Schunemann et al. } \\
\text { [82] }\end{array}$ & SGRQ, CRQ & $X$ & $X$ & & $\begin{array}{l}\text { - Excluded those with cognitive limitations } \\
\text { - Self-administration }\end{array}$ \\
\hline $\begin{array}{l}\text { Schunemann et al. } \\
\text { [83] }\end{array}$ & CRQ, SGRQ, SF-36 & $X$ & $X$ & & $\begin{array}{l}\text { - Excluded those with cognitive limitations } \\
\text { - Self-administration }\end{array}$ \\
\hline Sewell et al. [84] & CRQ & & $X$ & & - Self-administration \\
\hline Sewell et al. [85] & CRQ & X & $X$ & & $\begin{array}{l}\text { - Excluded patients with cognitive problems } \\
\text { - Self-administration }\end{array}$ \\
\hline Singh et al. [18] & CRQ, SGRQ & & $\mathrm{X}$ & & - Self-administration \\
\hline
\end{tabular}


Table 2 continued

\begin{tabular}{|c|c|c|c|c|c|}
\hline Study & PROMs involved & $\begin{array}{l}\text { Explicit } \\
\text { exclusion }\end{array}$ & $\begin{array}{l}\text { Implicit } \\
\text { exclusion }\end{array}$ & $\begin{array}{l}\text { Unclear } \\
\text { or no } \\
\text { evidence } \\
\text { of } \\
\text { exclusion }\end{array}$ & Notes \\
\hline Sprenkle et al. [21] & SF-36 & & $\mathrm{X}$ & & $\begin{array}{l}\text { - Self-administration } \\
\text { - Done by postal recruitment/survey }\end{array}$ \\
\hline Stapleton et al. [86] & SGRQ & $\mathrm{X}$ & $\mathrm{X}$ & & $\begin{array}{l}\text { - Excluded people with "mental status that } \\
\text { precluded participation" } \\
\text { - Self-administration }\end{array}$ \\
\hline Tashkin et al. [87] & SGRQ & & & $\mathrm{X}$ & \\
\hline Tonnel et al. [88] & VSRQ & & & $\mathrm{X}$ & \\
\hline Tsai et al. [89] & CRQ & & & $\mathrm{X}$ & \\
\hline $\begin{array}{l}\text { Viramontes and } \\
\text { O'Brien [90] }\end{array}$ & SF-36 & & & $\mathrm{X}$ & \\
\hline Williams et al. [91] & CRQ & & $\mathrm{X}$ & & - Self-administration \\
\hline Williams et al. [20] & CRQ & & $\mathrm{X}$ & & - Self-administration \\
\hline Wilson et al. [92] & SGRQ, SF-36 & & $\mathrm{X}$ & & - Self-administration \\
\hline Wyrwich et al. [22] & SF-36 & & & $\mathrm{X}$ & \\
\hline Xue et al. [93] & CAT & & $X$ & & - Recruitment through media advertising \\
\hline Yeo et al. [94] & SGRQ & & $\mathrm{X}$ & & - Self-administration \\
\hline Yohannes et al. [95] & CRQ & & & $X$ & \\
\hline Yount et al. [24] & FACIT-Dyspnea Scale & & $\mathrm{X}$ & & - Self-administration \\
\hline
\end{tabular}

CAT COPD Assessment Test, COPD chronic obstructive pulmonary disease, CRQ Clinical Respiratory Questionnaire, DIRECT Disability Related to COPD Tool, EXACT EXAcerbations of Chronic Obstructive Pulmonary Disease Tool, FACIT Functional Assessment of Chronic Illness Therapy, PROM patient-reported outcome measure, SQRQ St George's Respiratory Questionnaire, VSRQ Visual Simplified Respiratory Questionnaire

However, the latter study did use telephone interviews. Ringbaek et al. [23] found patients needed a lot of assistance to complete PROMs, particularly those with less education, and especially while attempting the SGRQ. Yount et al. [24] were explicit about their sample's high education level and used a touch screen to administer the FACIT-Dyspnea Scale. Technology was also used to send automatic alerts through an e-diary to support patients to complete the Capacity of Daily Living during the Morning Questionnaire [25].

\section{Discussion}

We have found that people with low literacy skills or learning disabilities are excluded from the development of PROMs for COPD in two distinct ways: explicitly through the study eligibility criteria and, of potentially greater significance, implicitly through recruitment or administration processes. These results indicate that these groups may struggle to complete PROMs. Healthcare initiatives like quality improvement for COPD that depend on PROMs may exclude people with low literacy skills or learning disabilities as a result.
Implicit exclusion is where researchers and readers may not realize exclusion takes place; we found implicit exclusion was most common largely due to the majority of studies' requirement for self-administration of the PROM. Almost all PROMs are only validated to be selfadministered but their readability and administration may be more or less inclusive. For example, technology support or easy read formatting can enhance accessibility. While some studies did use technology [24, 25], none of the papers we reviewed included discussion of the groups they potentially excluded in the recruitment processes they described. This could partly reflect the word limitations imposed on authors, but at least to some extent indicates a lack of critical awareness of the potential for exclusion. Where the authors did highlight heterogeneity in their sample demographic [24], we could not find specific mention of approaches to include people who may have low literacy skills or learning disabilities. There was also a lack of description of efforts to accommodate specific support to complete PROMs, for example through assisted completion. While other authors have found substantial disagreements between self- and proxy reporting especially to collect subjective information [26-28], the valid provision of assistance in 
completing PROMs has proved useful in population survey research, for example in Kaye [29].

Identifying and distinguishing forms of exclusion in research to develop PROMs is a prerequisite for future research aiming to make PROMs practice more inclusive. We consider implicit exclusion to be more concerning than explicit exclusion because it implies a lack of awareness of the potential for inequality in resulting healthcare and research practices. Studies with explicitly stated criteria excluding people with low literacy skills or learning disabilities set a clear barrier preventing them from participating. This suggests awareness on the part of the researchers and gives clear notification to readers that the findings apply only to the included population groups, provided this caveat is not overlooked when discussing generalizability [30]. Implicit exclusion practices have a higher likelihood than explicit exclusion to result in barriers to inclusive participation without any realization. The more recent increased focus on equality and diversity issues in research may improve future development practices compared with those used to develop the PROMs we identified. Inclusion might be given a higher priority and researchers given more support to overcome inevitable time, skill, and funding constraints that can limit feasibility to include people with low literacy skills or learning disabilities in their work. But if we do not realize there are barriers, we will not recognize the need for efforts to be more inclusive. In a current policy environment with increasing interest in PROMs [10], the potential result is unequal access to quality improvement processes.

Specific efforts can support the inclusion of people with low literacy skills or learning disabilities in research to develop PROMs. Research funders can confront issues of inequality by attaching equality criteria as a condition for funding the development of a PROM (similar to the requirement from the National Institutes of Health in the USA [31] to justify not making efforts to include groups normally left out of research). Responsibility among researchers to think through the implications of their methods and practices for people's ability to participate in their study may also be helpful. This may involve consulting service users in the commissioning, design, and conduct of research to determine best practice options for PROM development including when (timeliness), where (setting), and how (visual assistance) they can be administered, and any required assistance [32]. Other literature outlines issues and provides guidance to conduct research with people with learning disabilities [33], and tools to aid communication also exist [34]. Guidance on increasing the accessibility of information including the need for ample white space and large font sizes [35] are also easily applicable to typical research documents like information leaflets, consent forms, and PROM design. Our findings also suggested some promising results to build on. The e-diary with automatic alerts used to administer the Capacity of Daily Living during the Morning Questionnaire [25] and the touch screen used to administer the FACIT-Dyspnea Scale [24] may be promising as technology-based methods to support PROMs administration for people with low literacy skills or learning disabilities. These are similar to previous efforts to administer PROMs to people with low literacy skills in a cancer setting using an audiovisual touch screen [36].

Our work is a first step in highlighting the presence of exclusive practices in the development of PROMs and it has limitations. The findings have to be interpreted in the light of word limits imposed on article length. We did not infer sample demographics, recruitment, or administration practices where they were not explicitly stated in the studies and authors' descriptions of these may have in turn been limited by journal word counts. The data extraction was partly subjective as we sometimes assumed terms used by the authors to describe people who are not eligible for their study (like excluding those with 'cognitive impairments') would exclude someone with low literacy skills or learning disabilities. However, the extraction was checked by a second researcher to ensure consistency. Finally, we recognize that although people with low literacy skills and learning disabilities should not be 'lumped together' as one group, both groups face similar practical and functional challenges with reading and understanding written material. Other groups may also face similar exclusion from PROM development and validation processes, and substantial difficulties with PROMs, for example people with dementia or people with acquired brain injuries resulting in cognitive impairments.

\section{Conclusion}

While the use of PROMs is growing as a major part of healthcare quality improvement internationally, we have demonstrated that, at least in relation to COPD, people with low literacy skills or learning disabilities might be left out because they are not included in the research to develop PROMs. Most exclusion is implicit, suggesting the potential for lack of awareness of exclusionary practices. To prevent this form of exclusion in the future, efforts on the part of funders and researchers and more research into validating PROMs to be used with support through technology-based accessible completion or assisted completion are important. Ultimately PROMs are a promising opportunity to involve patients in quality improvement for COPD healthcare but the exclusive nature of PROM development may further alienate people with low literacy skills and learning disabilities from healthcare practices. 
Acknowledgments The research on which this paper is based is funded by the Technology Strategy Board and Healthcare Improvement Scotland, UK.

Author Contributions DJ conducted the initial search and data extraction and drafted the manuscript. KR, SW, and TK independently reviewed abstracts, verified data extraction, and edited the manuscript. All authors read and approved the final manuscript. SW acts as guarantor for the overall content.

Open Access This article is distributed under the terms of the Creative Commons Attribution Noncommercial License which permits any noncommercial use, distribution, and reproduction in any medium, provided the original author(s) and the source are credited.

\section{References}

1. DeWalt DA, Revicki DA. Importance of patient-reported outcomes for quality improvement. Rockville: Agency for Healthcare Research and Quality; 2008. http://qualitymeasures.ahrq.gov/ expert/expert-commentary.aspx?id=16466. Accessed 26 Jan 2012.

2. Scottish Government. The healthcare quality strategy for NHS Scotland. Edinburgh: Scottish Government; 2010. http://www. scotland.gov.uk/Resource/Doc/311667/0098354.pdf. Accessed 26 Jan 2012.

3. Coyne KS, Tubaro A, Brubaker L, Bavendam T. Development and validation of patient-reported outcomes measures for overactive bladder: a review of concepts. Urology. 2006;68(2 Suppl.): 9-16.

4. McKenna GS. Can learning disabilities explain low literacy performance? Gatineau: Human Resources and Social Development Canada; 2010.

5. National Literacy Trust. The Moser report. London: National Literacy Trust; 1999. http://www.literacytrust.org.uk/resources/ practical_resources_info/1770_the_moser_report. Accessed 26 Jan 2012

6. Mencap. More about learning disability. London: Mencap; 2008. http://www.mencap.org.uk/all-about-learning-disability/informationprofessionals/more-about-learning-disability. Accessed 26 Jan 2012.

7. Garcia SF, Hahn EA, Jacobs EA. Addressing low literacy and health literacy in clinical oncology practice. J Support Oncol. 2010;8(2):64-9.

8. Department of Health. Valuing people now: the delivery plan. London: Department of Health; 2009. http://www.dh.gov.uk/prod_ consum_dh/groups/dh_digitalassets/documents/digitalasset/dh_09 3371.pdf. Accessed 26 Jan 2012.

9. United Nations General Assembly. Final report of the Ad Hoc Committee on a Comprehensive and Integral International Convention on the Protection and Promotion of the Rights and Dignity of Persons with Disabilities. New York: UN; 2006.

10. Appleby J, Devlin NJ. Getting the most out of PROMS: putting health outcomes at the heart of NHS decision-making. London: The King's Fund; 2010. http://www.kingsfund.org.uk/publications/ proms.html. Accessed 26 Jan 2012.

11. Mencap. Health and Social Care Bill: memorandum submitted by Mencap [HS 18]. London: UK Parliament; 2011. http://www. publications.parliament.uk/pa/cm201011/cmpublic/health/memo/ m18.htm. Accessed 26 Jan 2012.

12. National Institute for Health and Clinical Excellence. Chronic obstructive pulmonary disease: costing report-implementing NICE guidance [CG 101]. London: NICE; 2011. http://www. nice.org.uk/nicemedia/live/13029/53292/53292.pdf. Accessed 26 Jan 2012.
13. Fitzpatrick R, Bowling A, Gibbons E, Haywood K, Jenkinson C, Mackintosh A, et al. A structured review of patient-reported measures in relation to selected chronic conditions, perceptions of quality of care and carer impact. Oxford: National Centre for Health Outcomes Development; 2006. http://phi.uhce.ox.ac.uk/ pdf/ChronicConditions/DH_REVIEWS_NOVEMBER_2007.pdf. Accessed 26 Jan 2012.

14. Davies N, Gibbons E, Fitzpatrick R. A structured review of patient-reported outcome measures for COPD: an update 2009. Oxford: University of Oxford; 2009. http://phi.uhce.ox.ac.uk/pdf/ COPD2009_FINAL.pdf. Accessed 26 Jan 2012.

15. Aaron SD, Vandemheen KL, Clinch JJ, Ahuja J, Brison RJ, Dickinson G, et al. Measurement of short-term changes in dyspnea and disease-specific quality of life following an acute COPD exacerbation. Chest. 2002;121(3):688-96.

16. Schofield MJ, Mishra G. Validity of the SF-12 Compared with the SF-36 Health Survey in Pilot Studies of the Australian Longitudinal Study on Women's Health. J Health Psychol. 1998;3(2): 259-71.

17. Maleki-Yazdi MR, Lewczuk CK, Haddon JM, Choudry N, Ryan N. Early detection and impaired quality of life in COPD GOLD stage 0: a pilot study. COPD: J Chronic Obstr Pulm Dis. 2007;4(4):313-20.

18. Singh SJ, Sodergren SC, Hyland ME, Williams J, Morgan MD. A comparison of three disease-specific and two generic health-status measures to evaluate the outcome of pulmonary rehabilitation in COPD. Respir Med. 2001;95(1):71-7.

19. Aiken LS, Butner J, Lockhart CA, Volk-Craft BE, Hamilton G, Williams FG. Outcome evaluation of a randomized trial of the PhoenixCare intervention: program of case management and coordinated care for the seriously chronically ill. J Palliat Med. 2006;9(1):111-26.

20. Williams JE, Singh SJ, Sewell L, Morgan MD. Health status measurement: sensitivity of the self-reported Chronic Respiratory Questionnaire (CRQ-SR) in pulmonary rehabilitation. Thorax. 2003;58(6):515-8.

21. Sprenkle MD, Niewoehner DE, Nelson DB, Nichol KL. The Veterans Short Form 36 questionnaire is predictive of mortality and health-care utilization in a population of veterans with a selfreported diagnosis of asthma or COPD. Chest. 2004;126(1):81-9.

22. Wyrwich KW, Nienaber NA, Tierney WM, Wolinsky FD. Linking clinical relevance and statistical significance in evaluating intra-individual changes in health-related quality of life. Med Care. 1999;37(5):469-78.

23. Ringbaek T, Martinez G, Lange P. A comparison of the assessment of quality of life with CAT, CCQ, and SGRQ in COPD patients participating in pulmonary rehabilitation. COPD: J Chronic Obstr Pulm Dis. 2012;9(1):12-5.

24. Yount SE, Choi SW, Victorson D, Ruo B, Cella D, Anton S, et al. Brief, valid measures of dyspnea and related functional limitations in chronic obstructive pulmonary disease (COPD). Value Health. 2011;14(2):307-15.

25. Partridge MR, Miravitlles M, Stahl E, Karlsson N, Svensson K, Welte T. Development and validation of the Capacity of Daily Living during the Morning questionnaire and the Global Chest Symptoms Questionnaire in COPD. Eur Respir J. 2010;36(1): 96-104.

26. Carod-Arta IF, Coral L, Trizotto D, Moreira C. Self- and proxyreport agreement on the stroke impact scale. Stroke. 2009;40: 3308-14.

27. Elliott MN, Beckett MK, Chong K, Hambarsoomians K, Hays $\mathrm{RD}$. How do proxy responses and proxy-assisted responses differ from what Medicare beneficiaries might have reported about their health care? Health Serv Res. 2008;43(3):833-48.

28. Hayley KL, Wangerman T. Using family members or close friends as informants about participation goals for older adults 
with and without Aphasia. Perspect Neurophysiol Neurogenic Speech Lang Disord. 2012;22(1):12-7.

29. Kaye HS. Inclusion of people with disabilities in the NHIS and NHIS-D: non-response, proxy response, and assisted response. In: Kroll T, Keer D, Placek P, Cyrill J, Hendershot G, editors. Towards best practices for surveying people with disabilities. Hauppage: NovaScience; 2007. p. 105-26.

30. Finlay WM, Lyons E. Methodological issues in interviewing and using self-report questionnaires with people with mental retardation. Psychol Assess. 2001;13(3):319-35.

31. Office of Legislative Policy and Analysis. Healthcare Equality and Accountability Act [H.R. 3459, S. 1833]. Bethesda: Office of Legislative Policy and Analysis; 2003. http://olpa.od.nih.gov/ legislation/108/pendinglegislation/heaa.asp. Accessed 26 Jan 2012.

32. Involve. http://www.involve.org.uk/. Accessed 27 Sep 2012.

33. Nind M. Conducting qualitative research with people with learning, communication and other disabilities: methodological challenges. Southampton: National Centre for Research Methods; 2008.

34. Talking Mats. http://www.talkingmats.com. Accessed 23 Mar 2012.

35. Mencap. Mencap's Make it Clear: a guide to making easy read information. London: Mencap; 2009. http://www.mencap.org.uk/ sites/default/files/documents/2008-04/ make\%20it\%20clear\%20apr09.pdf. Accessed 10 Feb 2012.

36. Hahn EA, Cella D, Dobrez D, Shiomoto G, Marcus E, Taylor SG, et al. The talking touchscreen: a new approach to outcomes assessment in low literacy. Psychooncology. 2004;13(2):86-95.

37. Aguilaniu B, Gonzalez-Bermejo J, Regnault A, Barbosa CD, Arnould B, Mueser M, et al. Disability related to COPD tool (DIRECT): towards an assessment of COPD-related disability in routine practice. Int J COPD. 2011;6:387-98.

38. Ashmore JA, Emery CF, Hauck ER, MacIntyre NR. Marital adjustment among patients with chronic obstructive pulmonary disease who are participating in pulmonary rehabilitation. Heart Lung. 2005;34(4):270-8.

39. Berry MJ, Adair NE, Rejeski WJ. Use of peak oxygen consumption in predicting physical function and quality of life in COPD patients. Chest. 2006;129(6):1516-22.

40. Bauldoff GS, Rittinger M, Nelson T, Doehrel J, Diaz PT. Feasibility of distractive auditory stimuli on upper extremity training in persons with chronic obstructive pulmonary disease. J Cardiopulm Rehabil. 2005;25(1):50-5.

41. Benzo R, Flume PA, Turner D, Tempest M. Effect of pulmonary rehabilitation on quality of life in patients with COPD: the use of SF-36 summary scores as outcomes measures. J Cardiopulm Rehabil. 2000;20(4):231-4.

42. Brightling CE, Monterio W, Green RH, Parker D, Morgan MD, Wardlaw AJ, et al. Induced sputum and other outcome measures in chronic obstructive pulmonary disease: safety and repeatability. Respir Med. 2001;95(12):999-1002.

43. Brown CD, Benditt JO, Sciurba FC, Lee SM, Criner GJ, Mosenifar Z, et al. Exercise testing in severe Emphysema: association with quality of life and lung function. J Chronic Obstruct Pulm Dis. 2008;5(2):117.

44. Carr SJ, Goldstein RS, Brooks D. Acute exacerbations of COPD in subjects completing pulmonary rehabilitation. Chest. 2007; 132(1):127-34.

45. Carrieri-Kohlman V, Nguyen HQ, Donesky-Cuenco D, DemirDeviren S, Neuhaus J, Stulbarg MS. Impact of brief or extended exercise training on the benefit of a dyspnea self-management program in COPD. J Cardiopulm Rehabil. 2005;25(5):275-84.

46. Coultas D, Frederick J, Barnett B, Singh G, Wludyka P. A randomized trial of two types of nurse-assisted home care for patients with COPD. Chest. 2005;128(4):2017-24.
47. Crockett AJ, Cranston JM, Moss JR, Alpers JH. The MOS SF-36 health survey questionnaire in severe chronic airflow limitation: comparison with the Nottingham Health Profile. Quality Life Res. 1996;5(3):330-8.

48. de Torres JP, Pinto-Plata V, Ingenito E, Bagley P, Gray A, Berger $\mathrm{R}$, et al. Power of outcome measurements to detect clinically significant changes in pulmonary rehabilitation of patients with COPD. Chest. 2002;121(4):1092-8.

49. Desikan R, Mason HL, Rupp MT, Skehan M. Health-related quality of life and healthcare resource utilization by COPD patients: a comparison of three instruments. Quality Life Res. 2002;11(8):739-51.

50. Dodd JW, Hogg L, Nolan J, Jefford H, Grant A, Lord VM, et al. The COPD assessment test (CAT): response to pulmonary rehabilitation. A multicentre, prospective study. Thorax. 2011;66(5): 425-9.

51. Eaton T, Lewis C, Young P, Kennedy Y, Garrett JE, Kolbe J. Long-term oxygen therapy improves health-related quality of life. Respir Med. 2004;98(4):285-93.

52. Fan VS, Ramsey SD, Make BJ, Martinez FJ. Physiologic variables and functional status independently predict COPD hospitalizations and emergency department visits in patients with severe COPD. COPD: J Chronic Obstruct Pulm Dis. 2007;4(1):29-39.

53. Gross NJ, Nelson HS, Lapidus RJ, Dunn L, Lynn L, Rinehart M, et al. Efficacy and safety of formoterol fumarate delivered by nebulization to COPD patients. Respir Med. 2008;102(2):189-97.

54. Gupta RB, Brooks D, Lacasse Y, Goldstein RS. Effect of rollator use on health-related quality of life in individuals with COPD. Chest. 2006;130(4):1089-95.

55. Guyatt GH, Berman LB, Townsend M, Pugsley SO, Chambers LW. A measure of quality of life for clinical trials in chronic lung disease. Thorax. 1987;42(10):773-8.

56. Guyatt GH, Townsend M, Keller J, Singer J, Nogradi S. Measuring functional status in chronic lung disease: conclusions from a randomized control trial. Respir Med. 1991;83(4):293-7.

57. Harper R, Brazier JE, Waterhouse JC, Walters SJ, Jones NM, Howard P. Comparison of outcome measures for patients with chronic obstructive pulmonary disease (COPD) in an outpatient setting. Thorax. 1997;52(10):879-87.

58. Hazell M, Frank T, Frank P. Health related quality of life in individuals with asthma related symptoms. Respir Med. 2003;97(11): $1211-8$.

59. Hinchcliff M, Beaumont JL, Thavarajah K, Varga J, Chung A, Podlusky S, et al. Validity of two new patient-reported outcome measures in systemic sclerosis: patient-reported outcomes measurement information system 29-item health profile and functional assessment of chronic illness therapy-dyspnea short form. Arthritis Care Res. 2011;63(11):1620-8.

60. Johnson MK, Birch M, Carter R, Kinsella J, Stevenson RD. Measurement of physiological recovery from exacerbation of chronic obstructive pulmonary disease using within-breath forced oscillometry. Thorax. 2007;62(4):299-306.

61. Jones PW, Quirk FH, Baveystock CM. The St George's Respiratory Questionnaire. Respir Med. 1991;85(Suppl. B):25-31 (discussion 33-7).

62. Jones PW, Bosh TK. Quality of life changes in COPD patients treated with salmeterol. Am J Respir Crit Care Med. 1997;155(4): $1283-9$.

63. Jones PW, Harding G, Berry P, Wiklund I, Chen WH, Kline LN. Development and first validation of the COPD Assessment Test. Eur Respir J. 2009;34(3):648-54.

64. Jones PW, Brusselle G, Dal Negro RW, Ferrer M, Kardos P, Levy ML, et al. Properties of the COPD assessment test in a crosssectional European study. Eur Respir J. 2011;38(1):29-35.

65. Jones PW, Tabberer M, Chen WH. Creating scenarios of the impact of COPD and their relationship to COPD Assessment Test (CATTM) scores. BMC Pulm Med. 2011;11:42. 
66. Leidy NK, Wilcox TK, Jones PW, Murray L, Winnette R, Howard K, et al. Development of the EXAcerbations of Chronic Obstructive Pulmonary Disease Tool (EXACT): a patient-reported outcome (PRO) measure. Value Health. 2010;13(8):965-75.

67. Mahler DA, Mackowiak JI. Evaluation of the Short-Form 36-item questionnaire to measure health-related quality of life in patients with COPD. Chest. 1995;107(6):1585-9.

68. Martin LL. Validity and reliability of a quality-of-life instrument: the chronic respiratory disease questionnaire. Cli Nurs Res. 1994;3(2):146-56.

69. McGlone S, Venn A, Walters EH, Wood-Baker R. Physical activity, spirometry and quality-of-life in chronic obstructive pulmonary disease. COPD: J Chronic Obstruct Pulm Dis. 2006;3(2): 83-8.

70. McKenna SP, Meads DM, Doward LC, Twiss J, Pokrzywinski R, Revicki D, et al. Development and validation of the living with chronic obstructive pulmonary disease questionnaire. Quality Life Res. 2011;20(7):1043-52.

71. Miller JD, Malthaner RA, Goldsmith CH, Goeree R, Higgins D, Cox PG, et al. A randomized clinical trial of lung volume reduction surgery versus best medical care for patients with advanced emphysema: a two-year study from Canada. Annals Thorac Surg. 2006;81(1):314-20.

72. Nagata K, Tomii K, Otsuka K, Tachikawa R, Otsuka K, Takeshita J, et al. Evaluation of the chronic obstructive pulmonary disease assessment test for measurement of health-related quality of life in patients with interstitial lung disease. Respirology. 2012;17(3):506-12.

73. Okubadejo AA, Jones PW, Wedzicha JA. Quality of life in patients with chronic obstructive pulmonary disease and severe hypoxaemia. Thorax. 1996;51(1):44-7.

74. Pakhale S, Wood-Dauphinee S, Spahija J, Collet JP, Maltais F, Bernard S, et al. Combining both generic and disease-specific properties: development of the McGill COPD quality of life questionnaire. COPD: J Chronic Obstruct Pulm Dis. 2011;8(4): 255-63.

75. Perez T, Arnould B, Grosbois JM, Bosch V, Guillemin I, Bravo ML, et al. Validity, reliability, and responsiveness of a new short Visual Simplified Respiratory Questionnaire (VSRQ) for healthrelated quality of life assessment in chronic obstructive pulmonary disease. Int J COPD. 2009;2009(4):9-18.

76. Petrillo J, Cairns J. Development of the EXACT-U: a preferencebased measure to report COPD exacerbation utilities. Value Health. 2011;14(4):546-54.

77. Puhan MA, Guyatt GH, Goldstein R, Mador J, McKim D, Stahl E, et al. Relative responsiveness of the Chronic Respiratory Questionnaire, St. George's Respiratory Questionnaire and four other health-related quality of life instruments for patients with chronic lung disease. Respir Med. 2007;101(2):308-16.

78. Punekar YS, Rodriguez-Roisin R, Sculpher M, Jones P, Spencer M. Implications of chronic obstructive pulmonary disease (COPD) on patients' health status: a western view. Respir Med. 2007;101(3):661-9.

79. Ries AL, Make BJ, Lee SM, Krasna MJ, Bartels M, Crouch R, et al. The effects of pulmonary rehabilitation in the national emphysema treatment trial. Chest. 2005;128(6):3799-809.
80. Roth MD, Connett JE, D'Armiento JM, Foronjy RF, Friedman PJ, Goldin JG, et al. Feasibility of retinoids for the treatment of emphysema study. Chest. 2006;130(5):1334-45.

81. Schunemann HJ, Guyatt GH, Griffith L, Stubbing D, Goldstein R. A randomized controlled trial to evaluate the effect of informing patients about their pretreatment responses to two respiratory questionnaires. Chest. 2002;122(5):1701-8.

82. Schunemann HJ, Griffith L, Jaeschke R, Goldstein R, Stubbing D, Guyatt GH. Evaluation of the minimal important difference for the feeling thermometer and the St. George's Respiratory Questionnaire in patients with chronic airflow obstruction. J Clin Epidemiol. 2003;56(12):1170-6.

83. Schunemann HJ, Griffith L, Jaeschke R, Goldstein R, Stubbing D, Austin $\mathrm{P}$, et al. A comparison of the original chronic respiratory questionnaire with a standardized version. Chest. 2003;124(4):1421-9.

84. Sewell L, Singh SJ, Williams JE, Collier R, Morgan MD. Can individualized rehabilitation improve functional independence in elderly patients with COPD? Chest. 2005;128(3):1194-200.

85. Sewell L, Singh SJ, Williams JE, Collier R, Morgan MD. How long should outpatient pulmonary rehabilitation be? A randomised controlled trial of 4 weeks versus 7 weeks. Thorax. 2006;61(9):767-71.

86. Stapleton RD, Nielsen EL, Engelberg RA, Patrick DL, Curtis JR. Association of depression and life-sustaining treatment preferences in patients with COPD. Chest. 2005;127(1):328-34.

87. Tashkin DP, Littner M, Andrews CP, Tomlinson L, Rinehart M, Denis-Mize K. Concomitant treatment with nebulized formoterol and tiotropium in subjects with COPD: a placebo-controlled trial. Respir Med. 2008;102(4):479-87.

88. Tonnel AB, Perez T, Grosbois JM, Verkindre C, Bravo ML, Brun M, et al. Effect of tiotropium on health-related quality of life as a primary efficacy endpoint in COPD. Int J COPD. 2008;3(2):301-10.

89. Tsai CL, Hodder RV, Page JH, Cydulka RK, Rowe BH, Camargo CA Jr. The short-form Chronic Respiratory Disease Questionnaire was a valid, reliable, and responsive quality-of-life instrument in acute exacerbations of chronic obstructive pulmonary disease. J Clin Epidemiol. 2008;61(5):489-97.

90. Viramontes JL, O'Brien B. Relationship between symptoms and health-related quality of life in chronic lung disease. J Gen Intern Med. 1994;9(1):46-8.

91. Williams JE, Singh SJ, Sewell L, Guyatt GH, Morgan MD. Development of a self-reported Chronic Respiratory Questionnaire (CRQ-SR). Thorax. 2001;56(12):954-9.

92. Wilson CB, Jones PW, O'Leary CJ, Cole PJ, Wilson R. Validation of the St. George's Respiratory Questionnaire in bronchiectasis. Am J Respir Crit Care Med. 1997;156(2 Pt 1):536-41.

93. Xue CC, Shergis JL, Zhang AL, Worsnop C, Fong H, Story D, et al. Panax ginseng C.A. Meyer root extract for moderate chronic obstructive pulmonary disease (COPD): study protocol for a randomised controlled trial. Trials. 2011;12:164.

94. Yeo J, Karimova G, Bansal S. Co-morbidity in older patients with COPD: its impact on health service utilisation and quality of life, a community study. Age Ageing. 2006;35(1):33-7.

95. Yohannes AM, Roomi J, Waters K, Connolly MJ. Quality of life in elderly patients with COPD: measurement and predictive factors. Respir Med. 1998;92(10):1231-6. 